\title{
The Impact of Acceptance \& Commitment Group Therapy on Pain-Related Acceptance in Veterans
}

\author{
David Cosio, Ph.D., ABPP* \\ Jesse Brown VA Medical Center, Anesthesiology/Pain Clinic, USA
}

\begin{abstract}
Background: The primary aim of the current study was to fill a gap in the literature by evaluating how an ACT for chronic pain group results in clinically meaningful changes in pain-related acceptance in a population of Veterans.

Methods: Ninety-four Veterans self-selected to participate in a 10-week ACT for chronic pain group. Paired samples $t$-tests were utilized to evaluate changes on the primary measure of pain acceptance whose domain scores are activities engagement and pain willingness and on secondary multidimensional outcomes.

Results: Veterans reported a significant increase in overall pain-related acceptance $(p<0.01, d=0.59)$. Both domains of acceptance, engagement in activities ( $p=0.01, d=0.51$ ) and pain willingness ( $p=0.03, d=0.37)$, showed a statistically significant difference. Secondary analyses found a significant increase in pain-related self-efficacy $(p<0.01, d=0.53)$.

Conclusions: The results of the present study indicate that the ACT for chronic pain group increased pain-related acceptance in Veterans, and this increase was driven by greater engagement in activities alike cognitive-behavioral therapy. ACT was also driven by greater willingness to experience pain, a concept unique to ACT. These outcomes support the goals of ACT, which are to advocate for willingness to accept unwanted private experiences that are out of personal control.
\end{abstract}

Keywords

Acceptance, Veterans, Chronic pain, Willingness, Self-efficacy

\section{Introduction}

Randomized controlled trials in adults with chronic pain suggest that Acceptance \& Commitment Therapy (ACT) is an efficacious alternative treatment to cognitive-behavioral therapy (CBT), despite the longer history of evidence supporting CBT's use to treat enduring pain [1,2]. Past research has also shown that both ACT and CBT for chronic pain interventions decrease pain intensity, disability, and distress [3], pain interference [2], and illness-focused coping, catastrophizing, and global distress levels [4]. Conversely, these interventions have been shown to increase readiness to adopt a self-management approach [5], and quality of life, life satisfaction, and functioning [6].

Acceptance, however, may not be a unique concept to ACT. Acceptance of pain has been defined as acknowledging that one has pain, giving up unproductive attempts to control pain, acting as if pain does not necessarily imply disability, and being able to commit one's efforts toward living a satisfying life despite pain [7]. The construct of acceptance can be further broken down into two domains: activities engagement, or one's willingness to engage in life activities despite pain, and pain willingness, or acknowledgement that avoidance and control are ineffective strategies [8]. The goal of ACT is for patients to learn to acquiesce to their pain, instead of hoping to eliminate or reduce pain while continuing to engage in a meaningful life [9]. Research has found that ACT for chronic pain increases pain acceptance, psychological flexibility, and functioning [10,11]. Vowles and colleagues [3] were surprised to be the first to find that both ACT and CBT increased pain acceptance over time. In addition, Åkerblom and colleagues [12] proposed that pain-related acceptance may be a key therapeutic process in CBT underlying the direct focus on challenging maladaptive beliefs and behavioral patterns. However, there is limited literature that suggests that $A C T$ and $C B T$ result in comparable changes in pain-related acceptance [2]. Wetherell and colleagues [2] assessed pain-related acceptance as a potential mediator of ACT in their

*Corresponding author: David Cosio, Ph.D., ABPP, Jesse Brown VA Medical Center, Anesthesiology/Pain Clinic, $820 \mathrm{~S}$. Damen Ave. \#124, Chicago, IL, 60612, USA, Tel: (312)-569-8703

Accepted: May 06, 2021

Published online: May 08, 2021

Citation: Cosio D (2021) The Impact of Acceptance \& Commitment Group Therapy on Pain-Related Acceptance in Veterans. J Psychiatry Treat Res 3(1):56-64 
study, but mediation analyses were not conducted because both groups experienced comparable, statistically significant increases in pain-related acceptance. Recently, Cosio and Ariel-Donges [13] found that CBT's focus on modifying maladaptive behaviors may inadvertently increase acceptance of chronic pain via decreased behavioral avoidance. Thus, it remains unclear how ACT may impact pain-related acceptance differently from CBT.

Findings from a previous study suggests that ACT is an effective treatment in a larger sample $(N=50)$ of Veterans with chronic pain [4]. This was previously substantiated by two studies investigating group-administered, ACT for chronic pain interventions including small percentages of Veterans in their samples [2,3]. Vowles and colleagues [2] compared the outcomes of treatment with those achieved following a comparable CBT intervention in a sample of Veterans ( $N=$ 11), and found that improvements in most measures of outcome occurred for both groups. This analysis represented the first to test a relatively brief, group-based ACT intervention among Veterans. Wetherell and colleagues [2] randomly assigned Veterans (38.6\%; $N=44$ ) recruited through VA San Diego Healthcare System primary care clinics to an ACT group or a CBT group, and found that ACT participants improved on pain interference, depression, and pain-related anxiety. However, there were no significant differences in improvement between the treatment conditions on any other outcome variables.

Forty-eight percent of Veterans within the Department of Veteran Affairs (VA) healthcare settings experience pain on a regular basis [14]. Pain is one of the most common reasons Veterans consult with their primary care providers [15], and is one of the most prevalent symptoms reported by returning Veterans [16]. One study found that U.S. soldiers screened within 90 days of returning from a one-year combat tour in Iraq were two-to-four times more likely to have a migraine as compared to the general population [17]. An estimated $17.6 \%$ of Gulf War Veterans have also shown symptoms associated with fibromyalgia [18]. Veterans are often more complex in their presentation of chronic pain than the general population due to difficulties returning to civilian life and the influence of their past military service on their pain experience [19]. In fact, past research has found that past military service may contribute to a hypersensitivity to pain symptoms [2022].

It has become increasingly important to identify the processes by which pain interventions, such as ACT, work to achieve adaptive behavior change. Thus, the current study aimed to fill a gap in the literature by evaluating how an ACT for chronic pain group results in clinically meaningful changes in pain-related acceptance in a population of Veterans. The current study also examined the effect of ACT on standardized outcomes (i.e. self-efficacy, health locus of control, quality of life, and illness perception). For our primary aim, we hypothesized that ACT for chronic pain in a Veteran population would result in increased pain-related acceptance through pain willingness and activities engagement. For our secondary aim, we anticipated that ACT would significantly increase pain-related self-efficacy; increase internal health locus of control beliefs; improve quality of life; and decrease illness perception.

\section{Materials \& Methods}

\section{Participants}

A total of 1204 Veterans with mixed, idiopathic (back, neck, extremity, head, and fibromyalgia), chronic pain voluntarily participated in a 12-week patient pain education program at a Midwestern VA Medical Center between November 13, 2012 and October 23, 2014. Veterans were then given the opportunity to sign-up for either the ACT or CBT groups for chronic pain upon learning about the interventions. A total of 94 (8\%) Veterans self-selected to participate in the ACT for pain group intervention, of which 17 (18\%) dropped out of the program. Veterans voluntarily participated in the group and were free to withdraw at any time. Veterans were given free parking validation or transportation reimbursement when in attendance and if qualified for such programs. Pre- and post-intervention assessments were collected for quality assurance purposes. Approximately $56 \%$ of the sample $(N=53)$ completed both the pre-and post-intervention assessments, and their responses were included in the current study (Figure 1). A limited medical records review was conducted as part of the current study to retrospectively determine the number of ACT sessions attended, age at time of treatment, sex, and race/ethnicity. The current study was reviewed and approved by the affiliated university's Institutional Review Board and the VA's Research and Development Office. A waiver of informed consent was granted due to the retrospective nature of the study and the minimal risks to participants.

\section{Intervention}

ACT is a form of clinical behavior analysis employed in psychotherapy that uses acceptance and mindfulness strategies mixed with commitment and behavior-change strategies to increase psychological flexibility. ACT is a structured therapy with a lot of flexibility, and the experiences of the patient are key, not didactics. Broadly, ACT for chronic pain involves experiential exercises related to six core skills: willingness to accept a range of experiences, engagement with the present moment, observing of the self, defusion from thoughts, identifying values, and committing to values-aligned action [23]. The current 10-week ACT treatment group followed an amalgamation of established protocols $[24,25]$ and a self-help workbook [26]. The current manualized group intervention was generated by incorporating, organizing, and expanding upon the aforementioned works to develop an experiential, ACT consistent protocol that has been validated for the identified population [27]. Participants were seen on a weekly basis unless there was a holiday scheduled. Psychology trainee therapists who had been trained to work with Veterans co-facilitated the group interventions with a licensed VA psychologist certified in ACT. Employing trainee therapists to conduct the current group interventions is representative of how master's-level clinicians are responsible for more direct patient contact [28]. Past research has shown that trainee therapists with limited training in behavioral protocols produce positive outcomes [29]. All interventionists used standardized manu- 


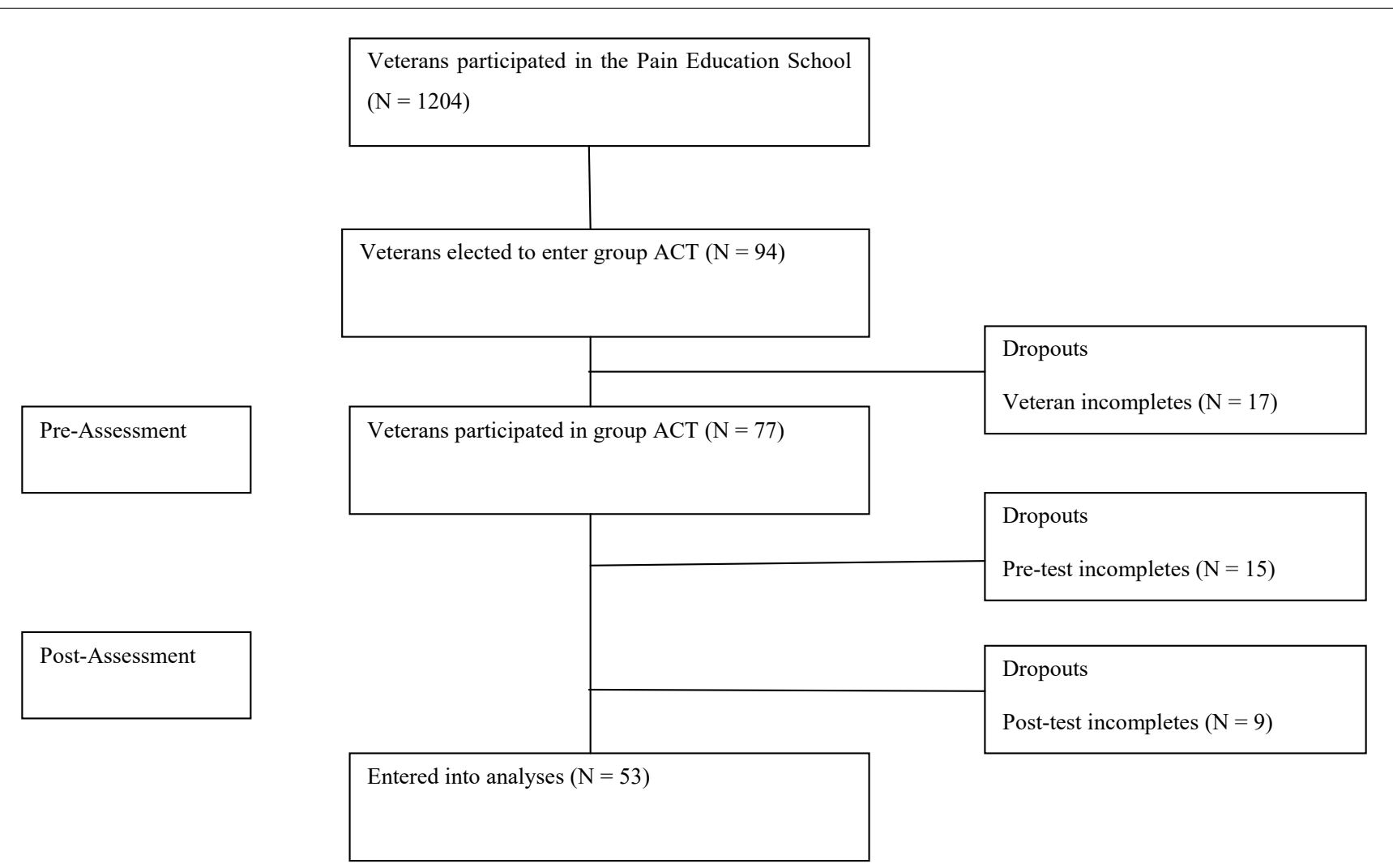

Figure 1: Flowchart of Study Participants.

als and received weekly supervision by a licensed clinical psychologist. Feedback, coaching, and consultations with trainee therapists were provided throughout the interventions to ensure fidelity of delivery of evidence-based practices.

\section{Measures}

As part of the introduction to the ACT group intervention, all participants completed a standard set of pre-intervention assessment measures. These measures were chosen based on their brevity and ease of administration, as well as, their reliability and validity in prior research. All participants were asked to complete the same battery of measures at post-intervention.

Chronic Pain Acceptance Questionnaire - Revised (CPAQ-R): The CPAQ-R is a 20-item questionnaire that assesses acceptance of chronic pain (McCracken, et al., 2004). Each question is answered using a 7-point Likert scale ranging from 0 ("never true") to 6 ("always true"). The CPAQ-R produces an overall pain acceptance score (ranging from 0-156) based upon two domain scores: Activities Engagement (i.e., willingness to engage in life activities despite pain; ranging from 0-66) and Pain Willingness (i.e., acknowledgement that avoidance and control are ineffective strategies; ranging from 0-54). Higher scores indicate greater acceptance of chronic pain. Prior studies indicate good to excellent internal consistency (Cronbach's $\alpha=0.82$ for Activity Engagement, Cronbach's $\alpha=0.78$ for Pain Willingness), construct validity when compared to validated measures of avoidance and distress, and predictive validity for pain-related disability [30,31]. Cronbach's alpha for the current study was acceptable for Ac- tivities Engagement ( $\alpha=0.84$ ) and overall CPAQ-R score ( $\alpha=$ $0.79)$, yet questionable for Pain Willingness $(\alpha=0.62)$.

Pain Self Efficacy Questionnaire (PSEQ): The PSEQ is a 10item questionnaire that evaluates respondents' confidence in their ability to perform specific activities while in pain within a range of scenarios, including household chores, work responsibilities, and coping without pain medication [32]. Each question is answered using a 7-point Likert scale ranging from 0 ("not at all confident") to 6 ("completely confident"). Overall PSEQ scores range from 0-60, with higher scores indicating greater self-efficacy for managing pain. Prior studies indicate excellent internal consistency (Cronbach's $\alpha=0.92$ ), high test-retest reliability at three months, and strong associations with other validated measures of pain self-efficacy [32]. Cronbach's alpha for the current study was excellent ( $\alpha=0.93$ ).

Multidimensional Health Locus of Control - Form C (MHLC-C): The MHLC-C is an 18-item questionnaire that assesses locus of control in individuals with a specific, identified medical condition (e.g., chronic pain) [33]. Each question is answered using a 6-point Likert scale ranging from 1 ("strongly disagree") to 6 ("strongly agree"). The MHLC-C contains four domains related to locus of control beliefs: Internality (personal choices control pain outcomes), Chance (luck or fate control pain outcomes), Doctors (medical treatments control pain outcomes), and Other People (other individuals control pain outcomes). Domain scores range from 6-36 for Internality and Chance and 3-18 for Doctors and Other People, with higher scores indicating stronger locus of control beliefs in that domain. Prior studies indicate good internal consistency for Internality $\alpha>0.85$ and for Chance $\alpha>0.79$, 
but acceptable internal consistency for Doctors $\alpha=0.71$ and for Other People $>0.70$ [33]. Cronbach's alpha for the current study was acceptable for Internality $(\alpha=0.81)$ and Chance $(\alpha=0.76)$, yet unacceptable for Doctors $(\alpha=0.55)$ and Other People $(\alpha=0.40)$. As such, the Doctors and Other People domains were not included in the present analyses.

World Health Organization Quality of Life - BREF (WHOQoL-BREF): The WHOQoL-BREF is a 26-item questionnaire that evaluates perceived quality of life across four domains: Physical Health, Psychological Health, Social Relationships, and Environment [34]. Each question is answered using a 5-point Likert interval scale ranging from 1 ("very poor," "very dissatisfied," or "not at all") to 5 ("very good," "very satisfied," or "an extreme amount"). Domain scale scores range from 0-100, with higher domain scores indicating better quality of life in that area. Prior studies indicate adequate internal consistency (Cronbach's $\alpha>0.70$ ), high reliability, and strong construct validity. Cronbach's alpha for the current study was acceptable for Psychological Health $(\alpha=0.71)$, Social Relationships $(\alpha=0.73)$, and Environment $(\alpha=0.83)$, yet unacceptable for Physical Health $(\alpha=0.53)$. As such, the Physical Health domain was not included in the present analyses.

Brief Illness Perception Questionnaire (IPQ-B): The IPQ-B is a 9-item questionnaire that evaluates cognitive and emotional dimensions of illness perceptions and can be tailored to a specific condition such as chronic pain $[35,36]$. Each item of the IPQ-B assesses a specific dimension of perceptions of chronic pain across nine domains: Consequences (impact of pain), Timeline (expected length of symptoms), Personal Control (ability to control pain), Treatment Control (effectiveness of treatment), Identity (number of symptoms), Concern (level of concern about pain), Understanding (ability to comprehend pain conditions), Emotional Response (emotional impact of pain), and Causes (causal factors for pain). For the first eight domains, each question is answered using an 11-point Likert scale ranging from 0 (e.g., "no effect at all," "no symptoms at all," "not at all concerned") to 10 (e.g., "severely affects my life," "many severe symptoms," "extremely concerned"). The final domain ("Causes") elicits a free-response rank order of three factors and was not included in the current study. An overall IPQ-B ranging from $0-80$ is derived from the sum of the first eight domains, with higher scores indicating a more negative or threatening (as opposed to benign) view of chronic pain. The IPQ-B has adequate internal consistency (Cronbach's $\alpha=0.72$ ), test-retest reliability, and concurrent validity $[35,37,38]$. Cronbach's alpha for the current study was unacceptable $(\alpha=0.58)$. As such, the IPQ-B was not included in the present analyses.

\section{Data analyses}

The current study used a quasi-experimental, one-group, pre/post-test design. One-way analyses-of-variance identified differences on demographic and outcome variables at baseline. Paired-samples $t$-tests were conducted to evaluate the effect of the intervention on the outcome variables from baseline to post-treatment. Outcome analyses used an efficacy subset analysis strategy which selects the subset of the patients who received the intended programming and who did not drop out for any reason.

Data were collected using paper measures and analyzed using PSPP, a free alternative to IBM's SPSS ${ }^{\circ}$ [39]. A Bonferroni correction was utilized to address the increased risk of type-I error due to multiple comparisons such that $(\alpha / 2=$ 0.03 ) was utilized as the cut-off for significance for the primary outcomes. A last-observation-carried-backward approach was used for missing pre-intervention assessment data [40], and a baseline-observation-carried forward approach was used for missing post-intervention assessment data [41]. Domain-level mean imputation was utilized for missing items on the MHLC-C, in accordance with scoring guidelines, where observation carried forward/backward was not possible. The Power and Sample Size Program [42] was utilized to verify sample size using an anticipated effect size (Cohen's d) of 0.50 , a desired statistical power level greater than or equal to 0.80 , and a probability level less than or equal to 0.05 . The minimum total sample size (pairs of subject scores) was $N=$ 33.

\section{Results}

\section{Participant characteristics}

Of the 53 Veterans who completed assessments at both timepoints, $72 \%(N=38)$ identified as African American, $22 \%$ $(N=12)$ as Caucasian, and $6 \%(N=3)$ as Hispanic/Latino. The majority of Veterans were male $(79 \%)$, yet a large percentage was female (21\%). Veterans were between the ages of 29-76 years-old at the time of treatment, with a mean age $( \pm$ SD) of 56.4 years $( \pm 10.2)$. The youngest returning Veterans (17-34 years-old) were not a well-represented $(N=2)$ age group in the current study. Veterans, on average, attended 85\% $(8.5$ sessions \pm 1.2 ) of the $10 \mathrm{ACT}$ group sessions, and treatment attendance ranged from $5-10$ sessions.

\section{Differences at baseline}

There were no significant baseline differences in race/ ethnicity, attendance, gender, or age ( $\left.p^{\prime} s>0.06\right)$ (Table 1$)$. Male participants were older than female participants $(p=$ 0.01). Latino participants scored significantly lower than the other racial groups on internality at baseline $(p=0.04)$. Past research has found that Latinos scored moderately low in external locus of control, suggesting they were internally oriented [43]. The oldest age groups scored significantly lower on illness perception at baseline when compared to the younger groups $(p=0.04)$. Older veterans appeared to have a more benign view of their chronic pain.

Primary outcomes: Veterans reported a significant increase in overall pain-related acceptance from baseline (48.98 $\pm 14.67)$ to post-treatment $(57.45 \pm 14.06), \mathrm{t}(52)=-5.14, p<$ $0.01, d=0.59$. The concept of acceptance was further investigated using its two domains. Engagement in activities scores from baseline $(32.25 \pm 11.91)$ to post-treatment (38.02 \pm 10.89), $\mathrm{t}(52)=-4.06, p=0.01, d=0.51$, and pain willingness scores from baseline $(16.74 \pm 6.95)$ to post-treatment $(19.43$ $\pm 7.63), \mathrm{t}(52)=-2.30, p=0.03, d=0.37$, increased significantly. The effect remained significant after the Bonferroni correction was utilized $(\alpha / 2=0.03)$. 


\begin{tabular}{|c|c|c|c|c|c|c|c|c|c|c|c|c|c|c|c|c|c|}
\hline & $a$ & $\begin{array}{l}n \\
o \\
0\end{array}$ & & & 苞 & & & & & & & $\stackrel{?}{?}$ & & & & * & \\
\hline & $u$ & ö & & & 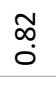 & & & & & & & $\begin{array}{l}R \\
i \\
-i\end{array}$ & & & & $\stackrel{\sim}{\sim}$ & \\
\hline $\begin{array}{l}\stackrel{0}{0} \\
\dot{\alpha} \\
\underline{0}\end{array}$ & $\frac{\overline{\hat{v}}}{\bar{\Sigma}}$ & & $\begin{array}{cc}\vec{m} & \bar{o} \\
\dot{m} & \dot{q} \\
\dot{n} & \underline{e}\end{array}$ & 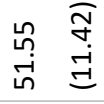 & & $\begin{array}{ll}8 & \overline{8} \\
\text { ñ } & \dot{0}\end{array}$ & 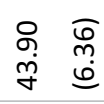 & 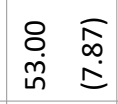 & 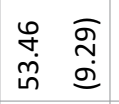 & 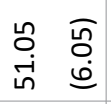 & $\begin{array}{ll}m & \bar{\beta} \\
\ddot{g} & \stackrel{\infty}{\sigma} \\
\stackrel{\infty}{n}\end{array}$ & & 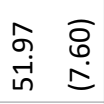 & $\begin{array}{cc}m & \bar{D} \\
\stackrel{n}{n} & \stackrel{\Sigma}{\Sigma}\end{array}$ & $\begin{array}{ll}\hat{b} & \bar{g} \\
\dot{g} & \ddot{g}\end{array}$ & & 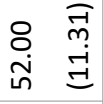 \\
\hline & $a$ & $\begin{array}{l}\infty \\
\infty \\
0\end{array}$ & & & $\stackrel{\hat{N}}{\hat{0}}$ & & & & & & & $\begin{array}{l}\infty \\
\infty \\
0\end{array}$ & & & & $\stackrel{\stackrel{n}{n}}{0}$ & \\
\hline 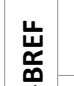 & 4 & $\begin{array}{l}0 \\
0 \\
0\end{array}$ & & & นึก & & & & & & & $\stackrel{4}{\stackrel{4}{0}}$ & & & & $\underset{\substack{0 \\
m \\
i}}{ }$ & \\
\hline $\begin{array}{l}0 \\
0 \\
\text { ⿳亠口冋 } \\
3\end{array}$ & $\begin{array}{l}\overline{\overline{\hat{v}}} \\
\bar{\Sigma}\end{array}$ & & $\begin{array}{ll}\hat{n} & \bar{g} \\
\dot{m} & \stackrel{\rho}{e}\end{array}$ & $\begin{array}{l}\stackrel{\bar{\Xi}}{\circ} \\
\dot{m}\end{array}$ & & $\begin{array}{ll}8 & \overline{8} \\
\dot{m} & \grave{0}\end{array}$ & $\begin{array}{cc}0 & \bar{i} \\
\substack{n \\
n} & \stackrel{0}{0}\end{array}$ & $\begin{array}{ll}\stackrel{8}{8} \\
\dot{m} & \stackrel{\Xi}{i}\end{array}$ & $\begin{array}{ll}\stackrel{\mathscr{n}}{0} \\
\stackrel{0}{0}\end{array}$ & 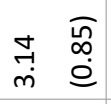 & $\begin{array}{ll}\underset{m}{\tilde{m}} & \bar{m} \\
\stackrel{\Xi}{\Xi}\end{array}$ & & $\begin{array}{ll}\tilde{m} & \stackrel{\infty}{\infty} \\
\dot{m} & \stackrel{\infty}{\varrho}\end{array}$ & 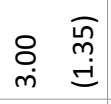 & 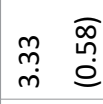 & & 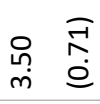 \\
\hline & $a$ & 暍 & & & $\begin{array}{l}\infty \\
0 \\
0\end{array}$ & & & & & & & $\begin{array}{l}* \\
0 \\
0\end{array}$ & & & & กู & \\
\hline 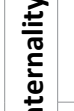 & 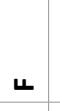 & $\begin{array}{l}8 \\
0 \\
0\end{array}$ & & & $\stackrel{\vec{n}}{\sim}$ & & & & & & & 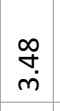 & & & & $\begin{array}{l}\text { L } \\
\infty \\
0 \\
0\end{array}$ & \\
\hline
\end{tabular}

\begin{tabular}{|c|c|c|c|c|c|c|c|c|c|c|c|c|c|c|c|c|}
\hline $\begin{array}{l}\widehat{\widehat{G}} \\
\stackrel{\Sigma}{\Sigma}\end{array}$ & & $\begin{array}{ll}\tilde{n} & \vec{A} \\
\stackrel{0}{N} & \stackrel{\varphi}{\varphi}\end{array}$ & $\begin{array}{ll}8 & \bar{\sigma} \\
\dot{n} & 0 \\
\end{array}$ & & $\begin{array}{ll}8 & \overline{0} \\
\stackrel{\sim}{i} & \vdots\end{array}$ & $\begin{array}{ll}0 & \overline{0} \\
\stackrel{0}{\infty} & \stackrel{5}{5}\end{array}$ & $\begin{array}{ll}\stackrel{\curvearrowright}{N} & \bar{N} \\
\stackrel{N}{N} & \infty\end{array}$ & $\begin{array}{ll}\tilde{N} & \bar{\Xi} \\
\tilde{N} & \underline{v}\end{array}$ & $\begin{array}{ll}\tilde{N} & \overline{\mathrm{o}} \\
\dot{\sim} & \underline{\varphi}\end{array}$ & $\begin{array}{ll}0 & \overline{\mathbf{Q}} \\
\stackrel{1}{0} & \infty \\
& \infty\end{array}$ & & 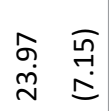 & 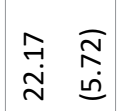 & $\begin{array}{ll}\underset{m}{m} & \bar{n} \\
\stackrel{m}{r} & \stackrel{\varphi}{\varphi}\end{array}$ & & $\begin{array}{ll}\stackrel{0}{0} \\
\stackrel{n}{n} & \stackrel{m}{m} \\
\stackrel{m}{\omega} & \end{array}$ \\
\hline a & 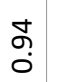 & & & 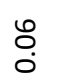 & & & & & & & 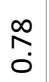 & & & & $\stackrel{\stackrel{n}{?}}{0}$ & \\
\hline $\boldsymbol{L}$ & ö & & & $\stackrel{\sim}{\sim}$ & & & & & & & $\stackrel{\sim}{0}$ & & & & $\stackrel{?}{\stackrel{2}{r}}$ & \\
\hline
\end{tabular}

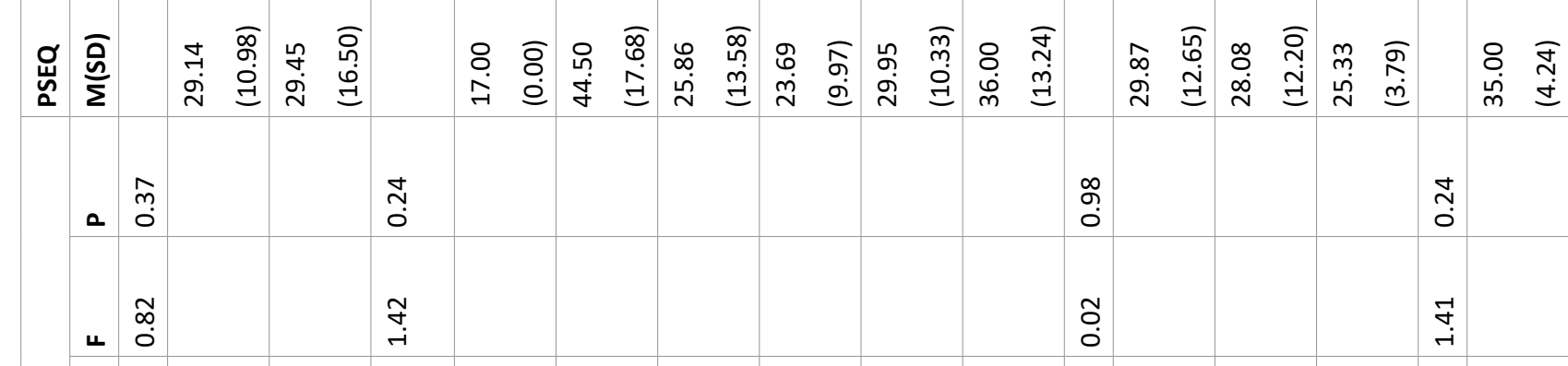

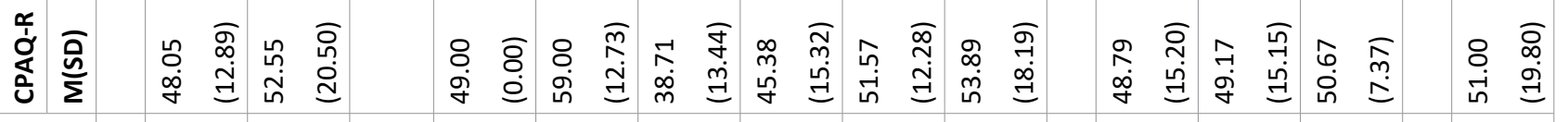

\begin{tabular}{|c|c|c|c|c|c|c|c|c|c|c|c|c|}
\hline & 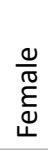 & & in & 6 & N & $\infty$ & $\sigma$ & 우 & & $\begin{array}{ll}8 \\
8 \\
2\end{array}$ & & 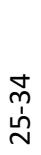 \\
\hline$\widehat{\S}$ & & 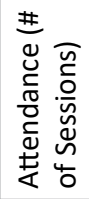 & & & & & & & $\pi$ & & & \\
\hline
\end{tabular}




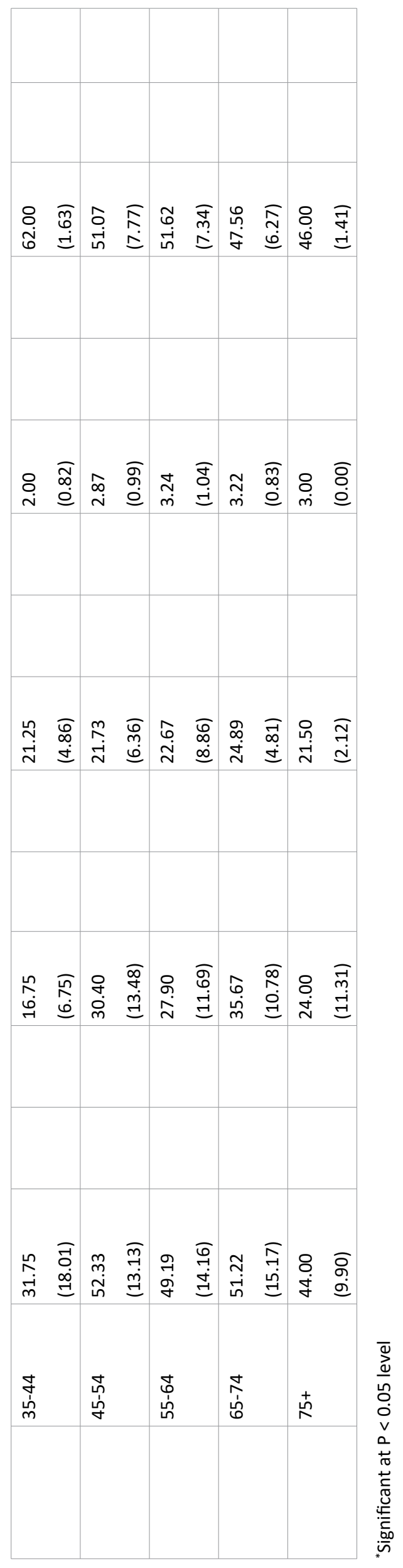


Citation: Cosio D (2021) The Impact of Acceptance \& Commitment Group Therapy on Pain-Related Acceptance in Veterans. J Psychiatry Treat Res 3(1):56-64

Table 2: Paired T-Tests of Primary \& Secondary Outcome Measures of Completers $(N=53)$.

\begin{tabular}{|c|c|c|c|c|c|}
\hline \multirow[t]{2}{*}{ Primary Variables } & \multirow[t]{2}{*}{$M$ diff (SD) } & \multirow[t]{2}{*}{$\boldsymbol{t}$} & \multirow[t]{2}{*}{ p-values } & \multicolumn{2}{|c|}{ 95\% Confidence Intervals } \\
\hline & & & & Lower & Upper \\
\hline \multicolumn{6}{|l|}{$\begin{array}{l}\text { Chronic Pain Acceptance } \\
\text { Questionnaire }\end{array}$} \\
\hline Activities Engagement & -5.77 & -4.06 & $0.00^{*}$ & -8.63 & -2.92 \\
\hline Pain Willingness & -2.70 & -2.30 & $0.03^{*}$ & -5.05 & -0.35 \\
\hline Secondary Variables & M diff (SD) & $\mathrm{t}$ & $p$-values & Lower & Upper \\
\hline Pain Self Efficacy Questionnaire & -5.92 & -4.47 & $0.00^{* *}$ & -8.59 & -3.26 \\
\hline \multicolumn{6}{|l|}{$\begin{array}{l}\text { Multidimensional Health Locus of } \\
\text { Control }\end{array}$} \\
\hline Internality & 0.38 & 0.48 & 0.63 & -1.20 & 1.95 \\
\hline Chance & -1.00 & -1.23 & 0.22 & -2.63 & 0.63 \\
\hline \multicolumn{6}{|l|}{$\begin{array}{l}\text { World Health Organization Quality } \\
\text { of Life }\end{array}$} \\
\hline Psychological Health & -3.28 & -1.68 & 0.10 & -7.22 & 0.65 \\
\hline Social & -4.04 & -1.38 & 0.17 & -9.90 & 1.83 \\
\hline Environment & -2.09 & -1.14 & 0.26 & -5.79 & 1.60 \\
\hline
\end{tabular}

"Significant at $p<0.03$ level after the Bonferroni correction; ${ }^{* *}$ Significant at $p<0.01$ level after the Bonferroni correction.

Secondary outcomes: There was a significant increase in pain-related self-efficacy from baseline $(29.21 \pm 12.14)$ to post-treatment $(35.13 \pm 10.06), \mathrm{t}(52)=-4.47, p<0.01, d$ $=0.53$. The effect remained significant after the Bonferroni correction was utilized $(\alpha / 6=0.01)$. There was no significant change in internal locus of control from baseline $(22.96 \pm$ $7.15)$ to post-treatment $(22.58 \pm 6.29), \mathrm{t}(52)=0.48, p=0.63$, nor in chance locus of control from baseline $(15.47 \pm 6.18)$ to post-treatment $(16.47 \pm 5.91), \mathrm{t}(52)=-1.23, p=0.22$. There was no significant change in psychological quality of life from baseline $(51.26 \pm 17.57)$ to post-treatment $(54.55 \pm 15.14)$, $\mathrm{t}(52)=-1.68, p=0.10$; social quality of life from baseline $(37.57 \pm 21.46)$ to post-treatment $(41.60 \pm 21.35), \mathrm{t}(52)=$ $-1.38, p=0.17$; nor in environmental quality of life from baseline $(55.32 \pm 17.76)$ to post-treatment $(57.42 \pm 17.07), t(52)=$ $-1.14, p=0.26$ (Table 2).

\section{Discussion}

The goal of Acceptance \& Commitment Therapy (ACT) is to reach acceptance of one's pain and suffering. People who suffer from chronic pain often have the most difficulty with the concept of acceptance. Often, people misconstrue this as meaning they have to accept needless suffering, give up all hope and feel defeated, accept someone else's version of their condition, or not care. Past research has found that ACT interventions have a large effect on pain acceptance [10]. However, the construct of acceptance has also been suggested to be a key therapeutic process in CBT [12]. There is evidence to suggests that $A C T$ and $C B T$ result in comparable changes in acceptance [2]. Recently, Cosio and Ariel-Donges [13] found that CBT's focus on modifying maladaptive behaviors inadvertently increased pain-related acceptance via decreased behavioral avoidance. Thus, it is plausible that ACT and CBT differ in the way in which they impact acceptance in
Veterans with chronic pain. The analyses of the present study provided support for our primary hypothesis regarding the impact of ACT on pain-related acceptance in Veterans. The results indicate that ACT increases pain-related acceptance through greater engagement in activities and willingness to experience pain, a concept that is unique to ACT. The ACT group intervention was found to produce changes in pain by increasing one's willingness to experience the pain and not engage in behaviors to decrease it. The group intervention was found to have a moderate effect on engagement in activities and a small to moderate effect on willingness to experience pain.

There are a number of personal factors that must be taken into account when working with chronic pain patients, including locus of control, self-efficacy, and quality of life. The analyses in the present study provided mixed support for our secondary hypotheses regarding the impact of ACT on these measures. The results indicate that ACT increased self-efficacy for pain management. Past research has shown that patients with higher self-efficacy rate pain stimuli as much less unpleasant than those with lower self-efficacy [44]. Given that self-management of chronic pain is essential for recovery, these results reinforce the utility of ACT as part of a comprehensive pain treatment for Veterans. The ACT intervention did not make a statistically significant change in internality or chance, which is somewhere between the illusion of control and powerlessness. These outcomes support the goals of ACT, which is to advocate for acceptance of unwanted private experiences that are out of personal control. In ACT, control is viewed as the problem. Patients learn that control works when manipulating external systems but can backfire when applied to private experiences, such as thoughts, feelings, and body sensations. People continue to engage in controlling behaviors because it works outside 
of the skin, they are taught that it should work by others, it appears to work for others (when comparing their insides to other's outsides), it sometimes works, and it should work if they try hard enough. In ACT, patients learn to understand the difference between things around them that are controllable versus uncontrollable.

ACT treatment aims at improving quality of life. However, the present study did not find that ACT impacted psychological, social, or environmental quality of life. Quality of life is inherently a dynamic, multi-level and complex concept, reflecting objective, subjective, macro-societal, and micro-individual, positive and negative influences which interact. There are also several variables, such as social support, self-esteem, coping, and personality traits, that act as mediators within the relationship between pain and quality of life [45]. In addition, improvements of quality of life are often small and fall short of normative values, indicating the need for future research. Null results in the current study may be related to statistical power, as this was a small sample of veterans with heterogenous forms of chronic pain, or to unique features of the Veteran population that moderate response to treatment and require further investigation.

The current study had some limitations. This study used a quasi-experimental, one group, pre/post-test design rather than a randomized control trial with a control group. Quasi-experimental designs are viable alternatives when preliminary testing is appropriate prior to further financial investment in a more definitive trial and system-wide dissemination. Future studies should replicate this intervention utilizing a randomized design with a no-treatment control and a larger sample size. All the participants in the current study had previously completed a health education program on pain self-management, which may suggest that a particularly motivated group of Veterans participated in the current study. Participants continued to engage in multidisciplinary pain treatment throughout the intervention period, which may have affected the scores on outcome measures. Therefore, results should be interpreted with caution and may not be generalizable to all chronic pain patients or even to all Veterans with chronic pain. Finally, the current sample was predominately African American, had a large sample of females, and returning Veterans (17-34 years-old) were not well-represented, which is not necessarily representative of the typical Veteran profile [46]. Maintaining the diversity of the sample and the presence of ongoing multidisciplinary treatment as usual, however, will be vital in future studies to the external validity of the research findings.

ACT and CBT are widely available evidence-based treatments for chronic pain offered to Veterans. The present study aimed to add to the current literature by exploring how ACT may impact pain-related acceptance differently from CBT. Results of the present study indicated that the ACT group intervention for Veterans increased pain-related acceptance, and this increase was driven by both greater engagement in activities and willingness to experience pain. Results further indicated that ACT increased self-efficacy for pain management, which is essential for recovery. Future studies should investigate the impact of ACT and CBT treatments on pain-re- lated acceptance in Veterans in order to compare the relative effect sizes and confirm the pattern of effects. Subsequent studies may also extend the field by exploring the impact of an integrated ACT/CBT intervention on these outcomes, the sequencing of $\mathrm{ACT}$ and $\mathrm{CBT}$ as consecutive treatments, and the optimal number of CBT or ACT sessions needed to increase pain-related acceptance to a clinically meaningful degree.

\section{Acknowledgements}

The authors would like to thank all the Veterans and providers who made this research possible. A special thanks to Mr. Leland Bardsley, Ms. Erin Lea, Ms. Jessica Pieczynski, Ms. Nicole Schechter, and Ms. Domonique Torbert for their assistance in conducting the Pain ACT Groups and the data collection. I would also like to thank Ms. Aviva Ariel-Donges for her assistance with data imputation and statistical analyses. The author would like to especially thank the Anesthesiology/Pain Clinic Department, Jesse Brown VA Medical Center, for their vision and ongoing support of the Pain Psychology program. This research did not receive any specific grant from funding agencies in the public, commercial, or not-for-profit sectors.

\section{Disclosure of Interest Statement}

The authors report no conflict of interest.

\section{References}

1. Veehof M, Oskam M, Schreurs K, et al. (2011) Acceptance-based interventions for the treatment of chronic pain: A systematic review and meta-analysis. Pain 152: 533-542.

2. Wetherell J, Afari N, Rutledge T, et al. (2011) A randomized, controlled trial of acceptance and commitment therapy and cognitive-behavioral therapy for chronic pain. Pain 152: 2098-2107.

3. Vowles K, Wetherell J, Sorrell J (2009) Targeting acceptance, mindfulness, and values-based action in chronic pain: Findings of two preliminary trials of an outpatient group-based intervention. Cognitive \& Behavioral Practice 16: 49-58.

4. Cosio D, Schafer $T$ (2015) Implementing an acceptance \& commitment therapy group protocol with veterans using VA's stepped care model of pain management. Journal of Behavioral Medicine 38: 984-997.

5. Jensen M, Nielson W, Kerns R (2003) Toward the development of a motivational model of pain self-management. The Journal of Pain 4: 477-492.

6. Forman E, Herbert J, Moitra E, et al. (2007) A randomized controlled effectiveness trial of acceptance and commitment therapy and cognitive therapy for anxiety and depression. Behavior Modification 31: 772-799.

7. Hayes S, Jacobson N, Follette V, et al. (1994) Acceptance and change: Content and context in psychotherapy. Context Press, Reno, NV.

8. McCracken L, Vowles K, Eccleston C (2004) Acceptance of chronic pain: Component analysis and a revised assessment method. Pain 107: 159-166.

9. Hayes S, Duckworth M (2006) Acceptance and commitment therapy and traditional cognitive behavior therapy approaches to pain. Cognitive and Behavioral Practice 13: 185-187. 
10. Hughes L, Clark J, Colclough J, et al. (2017) Acceptance and commitment therapy (ACT) for chronic pain. The Clinical Journal of Pain 33: 552-568.

11. Veehof M, Trompetter H, Bohlmeijer E, et al. (2016) Acceptance and mindfulness-based interventions for the treatment of chronic pain: A meta-analytic review. Cognitive Behaviour Therapy 45: 5-31.

12. Åkerblom S, Perrin S, Fischer M, et al. (2015) The mediating role of acceptance in multidisciplinary cognitive-behavioral therapy for chronic pain. The Journal of Pain 16: 606-615.

13. Cosio D, Ariel-Donges A (2020) Does cognitive behavioral therapy increase acceptance of chronic pain amongst veterans? Journal of Behavioral and Cognitive Therapy 30: 283-290.

14. Kerns R, Otis J, Rosenberg R, et al. (2003) Veterans' reports of pain and associations with ratings of health, health-risk behaviors, affective distress, and use of the healthcare system. Journal of Rehabilitation \& Research Development 40: 371-379.

15. Mitchinson A, Kerr E, Krein S (2008) Management of chronic noncancer pain by VA primary care providers: When is pain control a priority? American Journal of Managed Care 14: 77-84.

16. Gironda R, Clark M, Massengale J, et al. (2006) Pain among veterans of operations enduring freedom and Iraqi freedom. Pain Medicine 7: 339-343.

17. National Headache Foundation (2013) War Veterans Health Resource Initiative.

18. Yunus M (2012) The prevalence of fibromyalgia in other chronic pain conditions. Pain Res Treat.

19. Drake D, Beckworth W, Brown R, et al. (2006) A profile of patients in a VA pain clinic. Federal Practitioner 23: 15-22.

20. Dunphy R, Bridgewater L, Price D, et al. (2003) Visceral and cutaneous hypersensitivity in Persian Gulf war veterans with chronic gastrointestinal symptoms. Pain 102: 79-85.

21. Engel C, Jaffer A, Adkins J, et al. (2004) Can we prevent a second 'Gulf War syndrome'? Population-based healthcare for chronic idiopathic pain and fatigue after war. Adv Psychosom Med 25: 102-122.

22. Ford J, Campbell K, Storzbach D, et al. (2001) Post-traumatic stress symptomatology is associated with unexplained illness attributed to Persian Gulf War military service. Psychosomatic Medicine 63: 842-849.

23. Feliu-Soler A, Montesinos F, Gutiérrez-Martínez O, et al. (2018) Current status of acceptance and commitment therapy for chronic pain: A narrative review. J Pain Res 11: 2145-2159.

24. Dahl J, Wilson K, Luciano C, et al. (2005) Acceptance and commitment therapy for chronic pain. Context Press, Reno, NV.

25. Vowles K, Sorrell J (2007) Life with chronic pain: An acceptance-based approach (therapist guide and patient workbook). University of Bath, Bath.

26. Dahl J, Lundgren T (2006) Living beyond your pain: Using acceptance \& commitment therapy to ease chronic pain. New Harbinger, Oakland.

27. Cosio D (2019) A group-based, acceptance \& commitment therapy intervention for chronic pain. Journal of Social Work with Groups 43: 334-346.
28. Addis M, Krasnow A (2000) A national survey of practicing psychologists' attitudes toward psychotherapy treatment manuals. Journal of Consulting \& Clinical Psychology 68: 331-339.

29. Lappalainen R, Lehtonen T, Skarp E, et al. (2007) The impact of CBT and ACT models using psychology trainee therapists. Behavior Modification 31: 488-511.

30. McCracken L, Vowles K, Eccleston C (2019) Chronic Pain Acceptance Questionnaire - Revised (CPAQ-R).

31. Vowles K, McCracken L, McLeod C, et al. (2008) The Chronic Pain Acceptance Questionnaire: Confirmatory factor analysis and identification of patient subgroups. Pain 140: 284-291.

32. Nicholas M (2007) The Pain Self-Efficacy Questionnaire: Taking pain into account. European Journal of Pain 11: 153-163.

33. Wallston K, Strudler Wallston B, et al. (1978) Development of the multidimensional health locus of control (MHLC) scales. Health Education Monographs 6: 160-170.

34. WHOQOL Group (1996) WHOQOL-BREF: Introduction, administration, scoring and generic version of the assessment (field trial version).

35. Broadbent E, Petrie K, Main J, et al. (2006) The brief illness perception questionnaire. Journal of Psychosomatic Research 60: 631-637.

36. Broadbent E, Wilkes C, Koschwanez H, et al. (2015) A systematic review and meta-analysis of the Brief Illness Perception Questionnaire. Psychol Health 30: 1361-1385.

37. Basu S, Poole J (2016) The Brief Illness Perception Questionnaire. Occupational Medicine 66: 419- 420.

38. Løchting I, Garratt A, Storheim K, et al. (2013) Evaluation of the Brief Illness Perception Questionnaire in sub-acute and chronic low back pain patients: Data quality, reliability and validity. Journal of Pain \& Relief 2: 122.

39. Free Software Foundation (2015) GNU PSPP (Version 0.8.5). Boston, MA.

40. Blankers M, Koeter M, Schipper G (2010) Missing data approaches in ehealth research: Simulation study and a tutorial for non-mathematically inclined researchers. J Med Internet Res 12: e54.

41. Liu-Seifert H, Zhang S, D'Souza D (2010) A closer look at the baseline-observation-carried-forward (BOCF). Journal of Patient Preference \& Adherence 4: 11-16.

42. Dupont W, Plummer W (1997) PS Power and Sample Size program available for free on the Internet. Controlled Clinical Trials 18: 274.

43. Valentine S, Godkin J, Doughty G (2008) Hispanics' locus of control, acculturation, and wellness attitudes. Social Work in Public Health 23: 73-92.

44. Keefe F, Lefebvre J, Maixner W, et al. (1997) Self-efficacy for arthritis pain: Relationship to perception of thermal laboratory pain stimuli. Arthritis Care Research 10: 177-184.

45. Azizabadi Farahani M, Assari S (2010) Relationship between pain and quality of life. In: Preedy VR, Watson RR, Handbook of Disease Burdens and Quality of Life Measures. Springer, New York, NY.

46. American Community Survey (2018) Profile of Veterans: Data from the American Community Survey. National Center for Veterans Analysis and Statistics.

DOI: $10.36959 / 784 / 426$

Copyright: $@ 2021$ Cosio D. This is an open-access article distributed under the terms of the Creative Commons Attribution License, which permits unrestricted use, distribution, and reproduction in any medium, provided the original author and source are credited. 